Article

\title{
Arterial Offset Optimization Considering the Delay and Emission of Platoon: A Case Study in Beijing
}

\author{
Shenzhen Ding ${ }^{1}$, Xumei Chen ${ }^{1,2, * \mathbb{D}}$, Lei Yu ${ }^{2,3}$ and Xu Wang ${ }^{4}$ \\ 1 Key Laboratory of Transport Industry of Big Data Application Technologies for Comprehensive Transport, \\ Ministry of Transport, School of Traffic and Transportation, Beijing Jiaotong University, Beijing 100044, China \\ 2 School of Traffic and Transportation, Xuchang University, Xuchang 461000, Henan, China \\ 3 Department of Transportation Studies, Texas Southern University, Houston, TX 77004, USA \\ 4 China Railway Siyuan Survey and Design Group CO., LTD., Wuhan 430063, Hubei, China \\ * Correspondence: xmchen@bjtu.edu.cn; Tel.: +86-10-51684022
}

Received: 23 May 2019; Accepted: 12 July 2019; Published: 17 July 2019

check for updates

\begin{abstract}
The effective setting of offsets between intersections on arterial roads can greatly reduce the travel time of vehicles through intersections. However, coordinated control systems of urban arterial roads often do not achieve the desired effect. On the contrary, they are very likely to increase the traffic congestion on arterial roads, resulting in more delays of the platoon with more exhaust emissions, if the coordinated control system does not have effective settings. Meanwhile, taking into account increasing environmental pollution, measures are needed to solve the conflict between environmental and traffic management. Thus, in order to ensure the smooth flow of urban arterial roads while considering the environment, this paper develops a bi-objective offset optimization model, with reducing delays of the platoon on arterial roads as the primary objective, and reducing exhaust emissions as the secondary objective. The proposed bi-objective model is based on the division of platoon operating modes on arterial roads, and more pollutant types, including NOx, HC, and $\mathrm{CO}$, are considered when measuring environmental impact. Further, the modified hierarchical method, combining the branch and bound approach with the introductions of a relaxation coefficient, is employed to solve the model. By introducing a relaxation coefficient, the modified hierarchical method overcomes the defects of the traditional one. Finally, Xi Dajie Road in Beijing was taken as an example. The results showed that the bi-objective offset optimization model, considering both the delays and emissions of the platoon reduced delays by up to $20 \%$ and emissions by $7 \%$ compared with the existing timing plan. If compared with the offset optimization model considering delays only, such a model increases delays no more than $3 \%$ and reduces emissions by $6 \%$.
\end{abstract}

Keywords: urban arterial; offset optimization; bi-objective model; delays; exhaust emissions; platoon

\section{Introduction}

In urban transportation systems, reasonable adoption of coordinated control of arterial roads could ensure smooth flow and alleviate urban traffic congestion. The signal offset is an important parameter of the coordinated control on urban arteries, which decides the effect of the coordinated control for adjacent intersections and represents the time relationship, determined by the difference between a defined point in the coordinated green and a system reference point [1]. The signal offset has a considerable impact on the performance of the coordinated control system. The offset optimization of arterial roads can greatly reduce the travel time of vehicles, enhance stability, and smooth operation of urban traffic while improving arterial traffic congestion. However, the coordinated control system of urban arteries often does not achieve the desired effect, and can easily cause more traffic congestion, resulting in more delays of the platoon with more exhaust emissions, unless the coordinated control 
system have effective settings. Therefore, there is an urgent demand to quantify the impact of arterial offset optimization to improve coordinated control systems.

Furthermore, increasing motor vehicle ownership and use has greatly reduced traffic operation efficiency, resulting in a large number of exhaust emissions, and thus exacerbates urban air pollution [2]. Consequently, in order to reduce emissions from motor vehicles, it is necessary to take into account environmental impacts while improving urban transportation efficiency.

This paper develops a bi-objective arterial offset optimization model considering both delays and emissions of the platoon, including NOx, $\mathrm{HC}$, and $\mathrm{CO}$, to calculate optimal offsets between arterial intersections, which promotes the development of an eco-transportation system. In the model, the platoon operating modes on arterial roads are classified into four categories and the impact of the arterial platoon's spatio-temporal characteristics on emissions are fully reflected. More specifically, the VSP (Vehicle Specific Power) distribution calculation method [3-5] is adopted for emissions estimation of the platoon, and the operating situations of platoons passing through the downstream intersection are divided and modeled to optimize arterial offsets. The modified hierarchical method, combining the branch and bound approach with introduction of a relaxation coefficient, was employed to solve the bi-objective model. The final case study indicates the effectiveness and superiority of the model.

For the remainder of the paper, Section 2 is the literature review; Section 3 describes the study's methodology, including division of the platoon operating modes, estimation method of the platoon emissions, the offset optimization modeling, and the solution method; Section 4 presents a case study of Xi Dajie Road in Beijing in which the optimization model and the solution method were applied; followed by conclusions and recommendations in last section.

\section{Literature Review}

One of the keys to traffic signal coordination on arterial roads is to determine and optimize signal offsets. Signal offsets are typically determined by software packages that optimize offsets according to one of several mathematical objectives. Research on arterial traffic signal coordination can generally be divided into two categories: one is maximizing the bandwidth along an artery, which is the method of maximum green wave band; the other is minimizing the total delay for the signalized system, which is the minimum delay method [6-8].

The maximum green wave band method usually includes the graphic method and the numerical method. The graphic method is used to express the relationship between vehicle travel time and displacement on arterial roads using two-dimensional graphics. It is necessary to adjust the cycle length and velocity of "green wave" repeatedly in order to obtain a reasonable bandwidth when optimizing arterial offsets with the graphic method. However, the research on the maximum green wave band method has mostly focused on the improvement of the control algorithm, especially the numerical method, and relatively less research exists on the graphic method [9]. The numerical method is another way to optimize arterial offsets to determine the coordinated control parameters by a numerical calculation. Little's model maximizes two-way green bandwidths of a given artery so that vehicles may have larger chances to traverse the artery without any stops [10]. The model takes the form of a mixed-integer linear program, and can be solved to global optimum efficiently. This model lays the foundation for a large number of studies carried out over several decades. Wu et al. [11] proposed an approach for the application of bandwidth-oriented signal timing based on a group partition method. Guo et al. [12] employed a new two-direction green wave optimization method to solve the coordination problem of urban arteries based on MATLAB computation, in which five parameters, including the split, the offset, the phase sequence, the cycle time, and the phase, are optimized. In Li's paper, a two-phase approach was developed and it was proven that different optimal solutions may have different sensitivities to progression time uncertainty. Gomes [13] proposed a new formulation combining both the vehicle arrival functions and the relative offsets. Two models, which were established based on Little's bandwidth maximization model, have been proposed by Zhang et al. [14] to tackle traffic signal coordination problems for long arteries and grid networks. The 
numerical tests show that both models have the potential to produce coordination plans. Shirvani and Maleki [15] developed a new mixed integer variable bandwidth optimization model, in which the green splits, junctions' offsets, cycle length, and left turn phase sequences pattern are simultaneously optimized. It is worth mentioning that, in their study, arterial traffic signals were set based on fully acceptable or unacceptable thresholds for each arterial link-specific bandwidth and green split, which are specified by traffic engineers. Nunzio et al. [16] provided a method in which the problem of maximizing bandwidth along an artery is addressed by use of two combined control strategies: offsets and recommended speeds. In their study, the traffic energy consumption and network travel time were also considered in order to avoid impractical or undesirable solutions. Both graphical and numerical methods are applicable to the ideal situation in which the spacing between adjacent intersections is uniform. However, these two methods are not applicable to intersections with large spacing and unstable traffic flow. In practice, the maximum green wave band method has some disadvantages because the starting time of the green phase has an impact on vehicle passing. Only when the starting time of the green phase between adjacent intersections is equal to the optimal offset can the vehicle passing be maximized.

The minimum delay method is based on the correlation between offsets and platoon delays on the arterial roads. The primary objective of this method is to minimize the total delay of the platoon. The model is solved based on real-time information of arterial traffic flow, and optimal arterial offsets can be obtained. Lu et al. [17] developed a new offset model in which the total number of stops and the total delays are taken as the offset model output, and the rules of bidirectional traffic delay at the intersections are discussed. Li et al. [18] proposed an optimal offset model for traffic signal control systems of arterial roads, which introduced the idea of bidirectional signal control and aimed at the minimal delay of vehicles in each direction along the artery at the expected speed. He et al. [19] introduced a penalty to the model and the model achieved signal coordination based on a request-based mixed-integer linear program (MILP), which can accommodate multiple priority requests from different vehicles. The proposed control method was able to reduce average bus delay, average pedestrian delay, and average passenger car delay. Compared with the maximum green wave band method, the minimum delay method fully considers the variation of arterial traffic flow in order to seek optimal offsets. Further, the minimum delay method is more easily combined with environmental factors compared with the maximum green wave band method. In addition to delay-based models, some scholars have also optimized signals by queue-based models. For example, Song et al. [20] used the shockwave theory to analyze the queue evolution process under a saturated traffic environment. In order to avoid vehicle queue spillovers, an arterial offset optimization model was presented based on minimizing the queue length over the whole duration of the saturated traffic environment.

Moreover, with the increasing demand for environmental protection, some scholars have begun to consider the impact of environmental factors while optimizing signal timing. For example, Li et al. [21] analyzed the relationships between emissions, fuel consumption, vehicle delay, and the signal cycle length for an isolated intersection to optimize the green time and signal cycle length. Liao et al. [22], Park et al. [23], and Stevanovic et al. [24] optimized the signal timing while minimizing fuel consumption and vehicle emissions with the aid of traffic simulation software. Their study provided a fresh approach by which to integrate existing state-of-the-art tools for reassessing and ultimately minimizing fuel consumption and emissions. Micro-traffic simulation software VISSIM, CMEM (Comprehensive Modal Emission Model), and VISGAOST (an optimization program for signal timings of traffic controllers based on their performance in VISSIM microscopic simulation) are linked to optimize signal timings and minimize fuel consumption and $\mathrm{CO}_{2}$ emissions. Ma and Nakamura [25] optimized the cycle length for isolated signalized intersections considering the emission, and the cycle length minimizing emission is recommended to be applied under conditions of a high cruise speed or a high heavy vehicle percentage. These studies optimized the signal timing at the level of the link or isolated intersection, considering the environment. Meanwhile, a small number of scholars have begun to pay more attention to offset optimization considering delays and emissions. Madireddy et 
al. [26] examined the effect of a signal coordination strategy in an area of Antwerp, Belgium. The result showed that emission reductions by about $10 \%$ can be expected from the implementation of a green wave signal coordination scheme. Day et al. [27] introduced fuel consumption and $\mathrm{CO}_{2}$ emissions when they analyzed user benefits under different offset optimization plans for different goals. In these models, the optimization objectives use directly measured vehicle travel times to quantify delay, and only $\mathrm{CO}_{2}$ emissions are considered when quantifying environmental impact. The different platoon operating modes are also not discussed. Zhang et al. [28] formulated an offset optimization model to minimize delay and the risk associated with human exposure to traffic emissions. In order to minimize the total system delay and the mean excess exposure simultaneously, a signal timing optimization model was formulated to optimize the cycle length, offsets, green splits, and phase sequences, which is solved via a simulation-based genetic algorithm. These studies take into account the environmental benefits, and the developed models are employed to capture the dispersion of air pollutants. However, the pollutant types have generally only included $\mathrm{CO}_{2}$ in previous research, and little consideration has been given to the spatio-temporal operating characteristics of the platoon on arterial roads. Based on these studies, the types of emissions and the platoon's spatio-temporal operating characteristics have been fully considered for offset optimization in this paper, which may have a great impact on delays and emissions.

Thus, compared with the existing offset optimization methodologies, this paper aimed to develop a bi-objective offset optimization model, with reducing delays of the platoon on arterial roads as the primary objective, and reducing the exhaust emissions as the secondary objective. The proposed bi-objective model is based on the division of platoon operating modes on arterial roads, and more pollutant types, including $\mathrm{NOx}, \mathrm{HC}$, and $\mathrm{CO}$, are considered when measuring environmental impact. Further, different from the existing methods, the modified hierarchical method combining the branch and bound approach with introduction of a relaxation coefficient has been employed to solve the model, given that the hierarchical method usually has some advantages when the target priority of multi-objective optimization is certain. By introducing a relaxation coefficient, the modified hierarchical method overcomes the demerit of the traditional one.

\section{Methodology}

The methodology of the paper is organized as follows. In Section 3.1, we make some assumptions and introduce the division of platoon operating modes: the platoon operating modes are divided into four categories. In Section 3.2, the estimation method of platoon emission on arterials is presented based on the assumptions, which explains how the input elements in the target model were calculated. The offset optimization model to be described in the case study is then presented in Section 3.3, followed by the solution method in Section 3.4.

\subsection{Division of Platoon Operating Modes}

In this section, the following assumptions are proposed:

1. Two situations when the platoon passes through the downstream intersection have been considered in this paper. The front part of platoon is blocked and the central or tail part of platoon is blocked;

2. The formation of the platoon is a single file formation;

3. The offset is the time difference between a defined point in the coordinated green and a reference point in the adjacent intersection.

Based on the above assumptions, the paper divides the arterial roads between adjacent intersections into four sections, including (1), (2), (3), and (4), as shown in Figure 1. 
Intersection

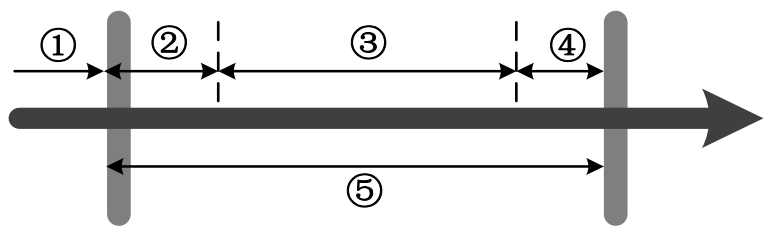

Figure 1. Artery division under the platoon operating modes.

Due to the influence of the queue at road sections (2)-(4), it is difficult to define the length of the acceleration and deceleration sections. Therefore, the paper proposes a method in which the sections (2)-(4) are taken as section (5), and platoon operating modes at the section (5) are divided into four categories, as shown in Table 1.

Table 1. Platoon operating modes between the adjacent intersections.

\begin{tabular}{cccccc}
\hline \multirow{2}{*}{ Modes } & \multicolumn{2}{c}{ Stop or Not } & \multicolumn{3}{c}{ Operation at Section (5) } \\
\cline { 2 - 6 } & $\boldsymbol{i}$ & $\boldsymbol{i}+1$ & Section (2) & Section (3) & Section (4) \\
\hline 1 & no & no & constant & constant & constant \\
2 & no & yes & constant & constant & deceleration \\
3 & yes & no & acceleration & constant & constant \\
4 & yes & yes & acceleration & constant & deceleration \\
\hline
\end{tabular}

\subsection{Estimation Method of Platoon Emission}

\subsubsection{Calculation of Emission Factors}

VISSIM can visually demonstrate the operating conditions of the entire traffic system and quickly output various traffic statistics, including vehicle delays, driving time, and queue length, etc. To calculate the emission factors, a VISSIM simulation model was developed based on field data collected from arterial roads in Beijing, which included road geometry, traffic volume, vehicle type, and signal control parameters. In order to ensure that the driving conditions of the vehicles in the simulation were close to those in the actual traffic, the simulation model was calibrated. In this paper, the driving behavior parameters of buses and passenger cars were calibrated until the calibration accuracy met the requirements. By constantly changing the random seeds in the simulation, the simulation results were analyzed and evaluated using the measured operation data. The driving behavior parameters of passenger cars and buses, including the desired deceleration value, the accepted deceleration, maximum deceleration in lane-changing, and look ahead or back distance in car-following, were calibrated in this paper. In order to verify the reliability of the platform, a VSP (vehicle specific power)-based approach was used in this paper for emission estimation, in which the emission factors were calculated using the real world data collected by a portable emission measurement system (PEMS). Moreover, the estimation errors for three emissions of NOx, HC, and CO, calculated using the simulation data and measured operation data, were compared. The mean absolute percentage errors (MAPE) for three emissions were $12.8 \%, 5.0 \%$, and $4.0 \%$ respectively, verifying the reliability of the simulation model. By constantly adjusting the offsets, the simulation scenarios can contain the abovementioned four platoon operating modes between adjacent intersections. In the paper, the platoon operation data under different modes were obtained according to the signal timing, vehicle travel distance, road number, and other parameters. In order to quantify emissions, the model parameters were defined first, as shown in Table 2. 
Table 2. Parameters for the emissions estimation.

\begin{tabular}{|c|c|c|c|c|c|}
\hline Variables & Definition & Unit & Variables & Definition & Unit \\
\hline$v$ & Instantaneous speed & $\mathrm{m} / \mathrm{s}$ & $a$ & $\begin{array}{l}\text { Instantaneous } \\
\text { acceleration }\end{array}$ & $\mathrm{m} / \mathrm{s}^{2}$ \\
\hline$m$ & Emission types & / & $j$ & $\begin{array}{l}\text { Vehicle specific power } \\
\text { (VSP) bin number }\end{array}$ & / \\
\hline$E T_{m}$ & $\begin{array}{l}\text { Total emissions from the } \\
\text { passenger cars or buses } \\
\text { within a certain road } \\
\text { section, for emission } \\
\text { type } m\end{array}$ & $\mathrm{~g} / \mathrm{km}$ & $E R_{j m}$ & $\begin{array}{l}\text { Emission rate of the bin } j \text {, } \\
\text { for the emission type } m\end{array}$ & $\mathrm{~g} / \mathrm{s}$ \\
\hline$D_{j}$ & $\begin{array}{l}\text { Distribution frequency } \\
\text { of the bin } j\end{array}$ & / & $V$ & Average speed & $\mathrm{m} / \mathrm{s}$ \\
\hline$E_{m}^{k}$ & $\begin{array}{l}\text { Emissions of the platoon } \\
\text { between the adjacent } \\
\text { intersections, for } \\
\text { emission type } m \text {, under } \\
\text { mode } k\end{array}$ & $\mathrm{~g}$ & $E F_{m}^{k}(v)$ & $\begin{array}{l}\text { Emission factors of the } \\
\text { passenger cars within a } \\
\text { certain road section, for } \\
\text { emission type } m \text {, under } \\
\text { mode } k\end{array}$ & $\mathrm{~g} / \mathrm{km}$ \\
\hline$E B_{m}^{k}(v)$ & $\begin{array}{l}\text { Emission factors of the } \\
\text { buses within a certain } \\
\text { road section, for } \\
\text { emission type } m \text {, under } \\
\text { mode } k\end{array}$ & $\mathrm{~g} / \mathrm{km}$ & $L_{i, i+1}$ & $\begin{array}{c}\text { Distance between stop } \\
\text { lines of the adjacent } \\
\text { intersections }\end{array}$ & $\mathrm{m}$ \\
\hline$Q_{i, i+1}$ & $\begin{array}{l}\text { Single-direction traffic } \\
\text { volume between the } \\
\text { adjacent intersections } \\
\text { during the study period }\end{array}$ & veh & $\mu_{i, i+1}$ & Bus ratio & / \\
\hline$t_{w}$ & $\begin{array}{l}\text { Time consumption of the } \\
\text { platoon head because of } \\
\text { the red phase }\end{array}$ & $\mathrm{s}$ & $E D_{1, m}$ & $\begin{array}{l}\text { Emission rate of the } \\
\text { passenger cars under the } \\
\text { condition of idling stop, } \\
\text { for emission type } m\end{array}$ & $\mathrm{~g} / \mathrm{s}$ \\
\hline$E D_{2, m}$ & $\begin{array}{l}\text { Emission rate of the } \\
\text { buses under the } \\
\text { condition of idling stop, } \\
\text { for emission type } m\end{array}$ & $\mathrm{~g} / \mathrm{s}$ & $\gamma_{m}$ & $\begin{array}{l}\text { Weight coefficient, for } \\
\text { emission type } m\end{array}$ & / \\
\hline$h_{i, i+1}$ & Number of stops & veh & $e_{i, i+1}$ & $\begin{array}{l}\text { Emissions for the } \\
\text { single-direction platoon } \\
\text { between the adjacent } \\
\text { intersections }\end{array}$ & $\mathrm{g}$ \\
\hline
\end{tabular}

VISSIM can record second-by-second speed and acceleration of each vehicle in the platoon to calculate the vehicle specific power (VSP). Based on the existing research [3,5,29], the VSP calculation of passenger cars is shown in Equation (1).

$$
V S P=v \times(1.1 a+0.132)+0.000302 v^{3}
$$

The VSP calculation of buses is expressed in Equation (2).

$$
V S P=v \times(a+0.09199)+0.000169 v^{3}
$$

where $v$ is the instantaneous speed in the unit of $\mathrm{m} / \mathrm{s}$; and $a$ is the instantaneous acceleration in the unit of $\mathrm{m} / \mathrm{s}^{2}$.

A total of 2 million vehicle second-by-second data were obtained after simulation, and the corresponding data were calculated by Equations (1) and (2). To obtain the VSP interval distribution of 
the platoon, the VSP value was divided into different bins at regular intervals. In this paper, $1 \mathrm{kw} / \mathrm{t}$ was used as an interval. The division principle is shown in Equation (3).

$$
\operatorname{VSP} \operatorname{Bin}=n, \forall: V S P \in[n-0.5, n+0.5]
$$

where $n$ is the integer from -20 to 20 for passenger cars and from -15 to 15 for buses.

In order to calculate the emission factors under different operating modes, the emission rate for each VSP bin should be obtained in advance, which is derived from the mass emission data based on existing research. According to the interval distribution of the platoon in different modes, emissions of the platoon on arterial roads in different modes can be calculated [3,29-31], as shown in Equation (4).

$$
E T_{m}=\frac{\sum_{j} E R_{j m} \times D_{j}}{V} \times 1000
$$

A specific explanation of the variables is shown in Table 2.

\subsubsection{Emissions Estimation}

For different modes, there are differences in the emissions estimation. For modes 1 and 3, vehicles in the platoon pass through the downstream intersection at a constant speed. The emissions are produced on the road section between intersections. For modes 2 and 4, in addition to the above emissions, the emissions from the idling stop at the downstream intersections are also included. Consequently, emissions of the platoon for different modes are calculated as follows.

Emissions for mode 1 are calculated with Equation (5).

$$
E_{m}^{1}=E F_{m}^{1}(v) \cdot L_{i, i+1} \cdot\left(1-\mu_{i, i+1}\right) Q_{i, i+1}+E B_{m}^{1}(v) \cdot L_{i, i+1} \cdot \mu_{i, i+1} \cdot Q_{i, i+1}
$$

Emissions for mode 2 are calculated with Equation (6).

$$
\begin{aligned}
E_{m}^{2}= & E F_{m}^{2}(v) \cdot L_{i, i+1} \cdot\left(1-\mu_{i, i+1}\right) Q_{i, i+1}+E D_{1, m} \cdot t_{w} \cdot\left(1-\mu_{i, i+1}\right) \cdot Q_{i, i+1} \\
& +E B_{m}^{2}(v) \cdot L_{i, i+1} \cdot \mu_{i, i+1} \cdot Q_{i, i+1}+E D_{2, m} \cdot t_{w} \cdot \mu_{i, i+1} \cdot Q_{i, i+1}
\end{aligned}
$$

Emissions for mode 3 are calculated with Equation (7).

$$
E_{m}^{3}=E F_{m}^{3}(v) \cdot L_{i, i+1} \cdot\left(1-\mu_{i, i+1}\right) Q_{i, i+1}+E B_{m}^{3}(v) \cdot L_{i, i+1} \cdot \mu_{i, i+1} \cdot Q_{i, i+1}
$$

Emissions for mode 4 are calculated with Equation (8).

$$
\begin{aligned}
E_{m}^{4}= & E F_{m}^{4}(v) \cdot L_{i, i+1} \cdot\left(1-\mu_{i, i+1}\right) Q_{i, i+1}+E D_{1, m} \cdot t_{w} \cdot\left(1-\mu_{i, i+1}\right) Q_{i, i+1} \\
& +E B_{m}^{4}(v) \cdot L_{i, i+1} \cdot \mu_{i, i+1} \cdot Q_{i, i+1}+E D_{2, m} \cdot t_{w} \cdot \mu_{i, i+1} \cdot Q_{i, i+1}
\end{aligned}
$$

A specific explanation of the variables is shown in Table 2.

According to the estimation methods of emissions under the four operating modes, combined with the stopping time and number of stops, emissions for the platoon on arterial roads can be estimated. For operating modes $1,2,3$, and 4 , the emissions, denoted as $\mathrm{e}_{1}, \mathrm{e}_{2}, \mathrm{e}_{3}$, and $\mathrm{e}_{4}$, can be calculated with Equations (9)-(12).

$$
\begin{aligned}
e_{1}= & \left(\sum_{m=1}^{3} \gamma_{m} E F_{m}^{1}(v)\right) \cdot L_{i, i+1} \cdot\left(1-\mu_{i, i+1}\right)\left(Q_{i, i+1}-h_{i, i+1}\right)+\left(\sum_{m=1}^{3} \gamma_{m} E B_{m}^{1}(v)\right) \cdot L_{i, i+1} \cdot \mu_{i, i+1} \cdot\left(Q_{i, i+1}-h_{i, i+1}\right) \\
e_{2} & =\left(\sum_{m=1}^{3} \gamma_{m} E F_{m}^{2}(v)\right) \cdot L_{i, i+1} \cdot\left(1-\mu_{i, i+1}\right) \cdot h_{i, i+1}+\left(\sum_{m=1}^{3} \gamma_{m} E D_{1, m}\right) \cdot t_{w} \cdot\left(1-\mu_{i, i+1}\right) \cdot h_{i, i+1} \\
& +\left(\sum_{m=1}^{3} \gamma_{m} E B_{m}^{2}(v)\right) \cdot L_{i, i+1} \cdot \mu_{i, i+1} \cdot h_{i, i+1}+\left(\sum_{m=1}^{3} \gamma_{m} E D_{2, m}\right) \cdot t_{w} \cdot \mu_{i, i+1} \cdot h_{i, i+1}
\end{aligned}
$$




$$
\begin{aligned}
e_{3}= & \left(\sum_{m=1}^{3} \gamma_{m} E F_{m}^{3}(v)\right) \cdot L_{i, i+1} \cdot\left(1-\mu_{i, i+1}\right)\left(Q_{i, i+1}-h_{i, i+1}\right)+\left(\sum_{m=1}^{3} \gamma_{m} E B_{m}^{3}(v)\right) \cdot L_{i, i+1} \cdot \mu_{i, i+1} \cdot\left(Q_{i, i+1}-h_{i, i+1}\right) \\
e_{4}= & \left(\sum_{m=1}^{3} \gamma_{m} E F_{m}^{4}(v)\right) \cdot L_{i, i+1} \cdot\left(1-\mu_{i, i+1}\right) \cdot h_{i, i+1}+\left(\sum_{m=1}^{3} \gamma_{m} E D_{1, m}\right) \cdot t_{w} \cdot\left(1-\mu_{i, i+1}\right) \cdot h_{i, i+1} \\
& +\left(\sum_{m=1}^{3} \gamma_{m} E B_{m}^{4}(v)\right) \cdot L_{i, i+1} \cdot \mu_{i, i+1} \cdot h_{i, i+1}+\left(\sum_{m=1}^{3} \gamma_{m} E D_{2, m}\right) \cdot t_{w} \cdot \mu_{i, i+1} \cdot h_{i, i+1}
\end{aligned}
$$

A specific explanation of the variables is shown in Table 2.

Thus, the estimation method of emissions for a single-direction platoon between adjacent intersections on arterial roads can be obtained, as shown in Equation (13).

$$
e_{i, i+1}=a e_{1}+b e_{2}+c e_{3}+d e_{4}
$$

where $e_{i, i+1}$ is the emissions for a single-direction platoon between the adjacent intersections on arterial roads, in the unit of $\mathrm{g} ; a, b, c$, and $d$ are the parameters and $[a, b, c, d]=\left[\begin{array}{l}1,0,0,0 \\ 0,1,0,0 \\ 0,0,1,0 \\ 0,0,0,1\end{array}\right]$. When the platoon operating mode accords with modes $1, a$ is equal to 1 . Otherwise, $a$ is equal to 0 . The rules of $b$, $c$, and $d$ are similar to that of $a$.

\subsection{Offset Optimization Modeling}

Suppose that the arterial system as shown in Figure 2 has a total of $\mathrm{n}$ intersections, respectively denoted as $P_{1}, \ldots P_{i}, P_{i+1}, \ldots, P_{n}$. West to east is the eastbound direction and east to west is the westbound direction. $L_{i, i+1}$ is the distance between adjacent intersections $P_{i}$ and $P_{i+1}$ with the unit of $\mathrm{m}$.

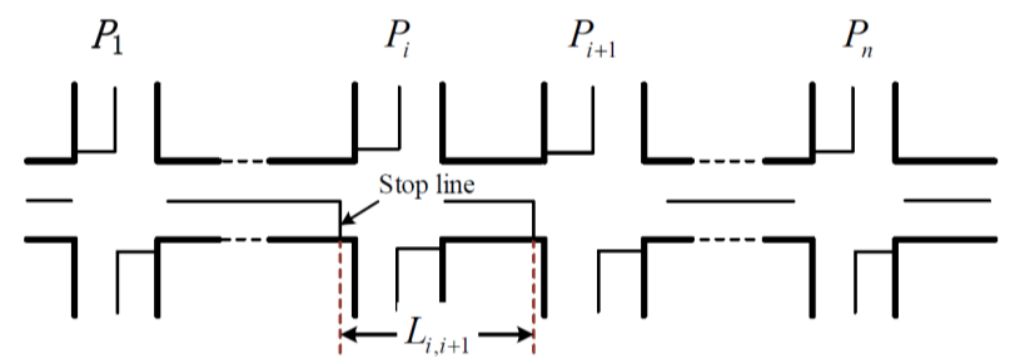

Figure 2. Diagram of the artery.

In order to establish an offset optimization model of the above arterial system, model parameters were defined first, as shown in Table 3. 
Table 3. Parameters for the offset delays estimation.

\begin{tabular}{cccccc}
\hline Variables & Definition & Unit & Variables & Definition & Unit \\
\hline$q_{i, i+1}$ & Eastbound arrival rate & veh/h & $v_{i, i+1}$ & $\begin{array}{c}\text { Average speed of the } \\
\text { eastbound platoons }\end{array}$ & $\mathrm{m} / \mathrm{s}$ \\
\hline$\varphi_{i, i+1}$ & $\begin{array}{c}\text { Relative offset between } \\
\text { the intersection } P_{i} \text { and } \\
P_{i+1}\end{array}$ & $\mathrm{~s}$ & $\mathrm{~T}$ & $\begin{array}{c}\text { Cycle length of the } \\
\text { arterial system }\end{array}$ & $\mathrm{s}$ \\
\hline$R_{i}$ & $\begin{array}{c}\text { Red time of the } \\
\text { intersection } P_{i}\end{array}$ & $\mathrm{~s}$ & $G_{i}$ & $\begin{array}{c}\text { Green time of the } \\
\text { intersection } P_{i}\end{array}$ & $\mathrm{~s}$ \\
\hline$M_{i}$ & $\begin{array}{c}\text { Maximum capacity of } \\
\text { the intersection } P_{i}\end{array}$ & $\mathrm{veh} / \mathrm{h}$ & $d_{i, i+1}$ & $\begin{array}{c}\text { Eastbound delay } \\
\text { between the } \\
\text { intersection } P_{i} \text { and } \\
P_{i+1}\end{array}$ & $\mathrm{~s}$ \\
\hline$D_{i}$ & $\begin{array}{c}\text { Unidirectional delay of } \\
\text { the arterial system }\end{array}$ & $\mathrm{s}$ & $\mathrm{D}$ & $\begin{array}{c}\text { Total delay of the } \\
\text { arterial system }\end{array}$ & $\mathrm{s}$ \\
\hline
\end{tabular}

\subsubsection{Primary Objective}

Suppose that $t_{i, i+1}$ is "the remainder travel time" of the platoons between intersection $P_{i}$ and $P_{i+1}$ with the unit of $\mathrm{s}$, and $t_{i, i+1}=\left[L_{i, i+1} / v_{i, i+1}\right](\bmod T)$. The $\left[L_{i, i+1} / v_{i, i+1}\right](\bmod T)$ represents the remainder of a division between $L_{i, i+1} / v_{i, i+1}$ and $T$, where all the intersections share the same cycle length. According to the assumptions in this paper, there are two different situations of traffic flow for the platoon, that is, the front part of platoon is blocked and the central or tail part of platoon is blocked, with the same probability.

\section{The front part of platoon is blocked}

As shown in Figure 3, vehicles in the front part of the platoon are blocked with the constraint of $0 \leq t_{i, i+1}<\varphi_{i, i+1}$. In this situation, vehicles in the front of platoon are blocked because of the red light, and vehicles in the central or tail part of platoon pass through the downstream intersection smoothly, with the assumption that the light turns green before the vehicles arrive at the intersections. The slope of straight line going through the origin indicates the eastbound rate of traffic flow $q_{i, i+1}$, which is the arrival rate.

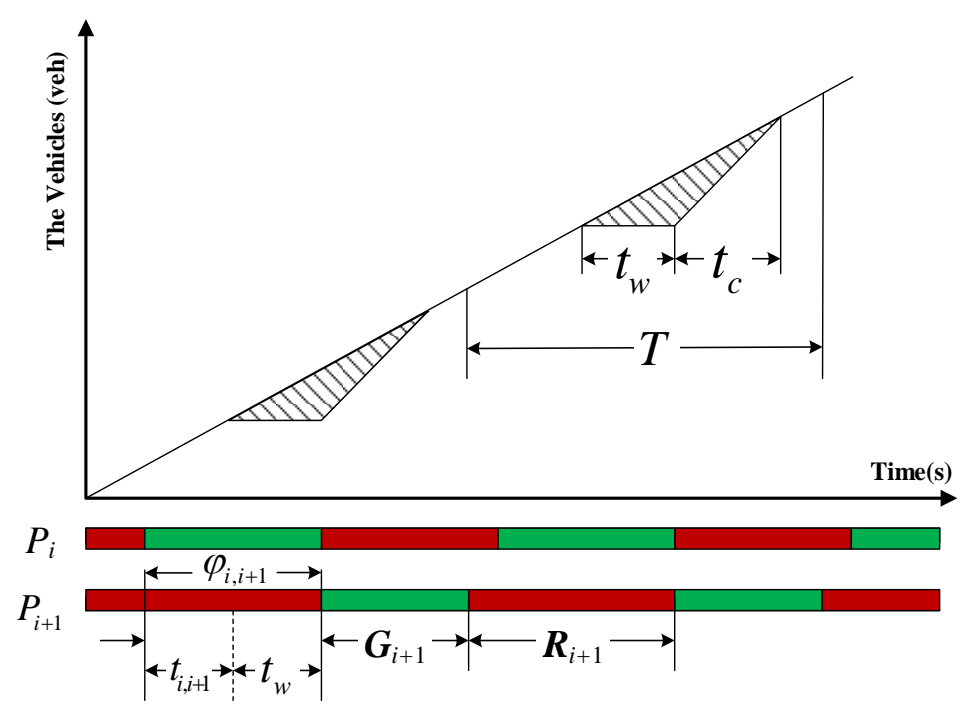

Figure 3. Delays when the front part of platoon is blocked. 
According to the definition of $t_{w}, \varphi_{i, i+1}=t_{i, i+1}+t_{w}$ is obtained and $t_{w}$ can be calculated with Equation (14).

$$
t_{w}=\varphi_{i, i+1}-t_{i, i+1}
$$

Suppose that $t_{c}$ is the queue dissipation time of platoon in a green phase in the unit of $\mathrm{s}$, in which the platoon at the intersection $P_{i+1}$ is given maximum capacity $M_{i+1}$ through the intersection and there is no vehicle queuing after $t_{c}$. Thus, $t_{c} \leq G_{i+1}$ and $\left(t_{w}+t_{c}\right) q_{i, i+1}=t_{c} M_{i+1}$ can be obtained. The dissipation time $t_{c}$ is calculated with Equation (15).

$$
t_{c}=\frac{t_{w} q_{i, i+1}}{M_{i+1}-q_{i, i+1}}
$$

The shaded area in Figure 2 shows the eastbound delay between intersections $P_{i}$ and $P_{i+1}$, denoted as $d_{i, i+1}^{1}$ in the unit of s. $d_{i, i+1}^{1}$ can be calculated with Equation (16).

$$
d_{i, i+1}^{1}=\frac{1}{2} t_{w} q_{i, i+1}\left(t_{w}+t_{c}\right)
$$

Substitute Equations (14) and (15) into Equation (16). The eastbound delay between intersection $P_{i}$ and $P_{i+1}$ is derived, as shown in Equation (17).

$$
d_{i, i+1}^{1}=\frac{\left(\varphi_{i, i+1}-t_{i, i+1}\right)^{2} M_{i+1} q_{i, i+1}}{2\left(M_{i+1}-q_{i, i+1}\right)}
$$

Additionally, suppose $h_{i, i+1}^{1}$ is the eastbound vehicle stops at the intersection $P_{i+1}$ in the unit of veh. $h_{i, i+1}^{1}$ can be calculated with Equation (18).

$$
h_{i, i+1}^{1}=q_{i, i+1}\left(t_{w}+t_{c}\right)=\frac{\left(\varphi_{i, i+1}-t_{i, i+1}\right) M_{i+1} q_{i, i+1}}{M_{i+1}-q_{i, i+1}}
$$

2. The central or tail part of platoon is blocked

As shown in Figure 4, vehicles in the central or tail part of platoon are blocked and the remaining vehicles of the platoon pass through the downstream intersection smoothly with the constraint of $\varphi_{i, i+1} \leq t_{i, i+1}<\varphi_{i, i+1}+G_{i+1}$.

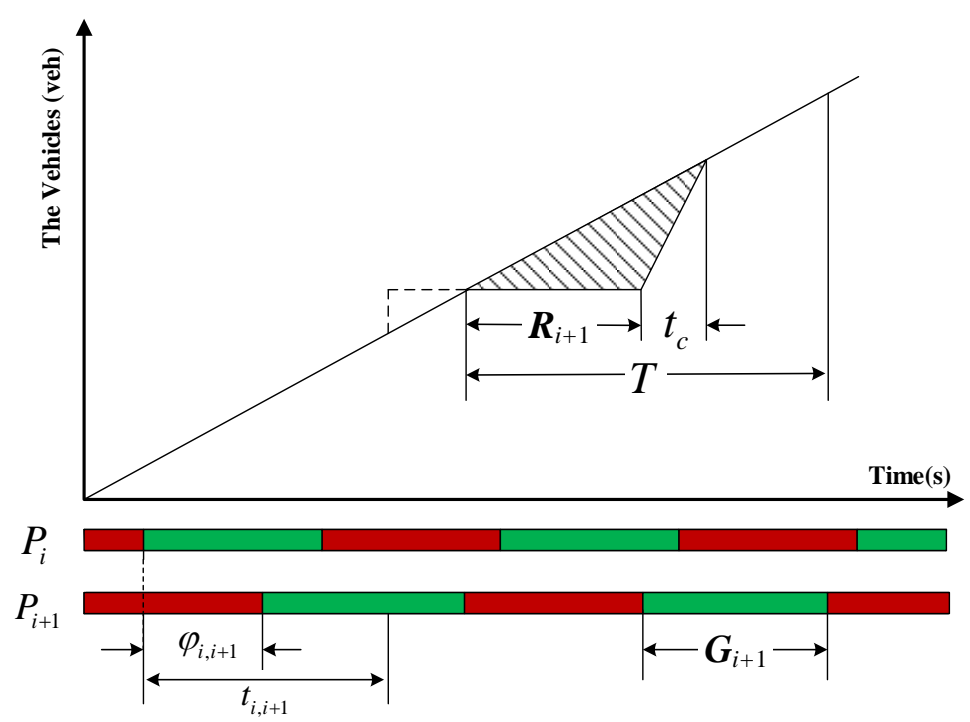

Figure 4. Delays when the central or tail part of platoon is blocked. 
Suppose $t_{w}^{\prime}$ is the remaining green time when platoon arrivals the downstream intersection in the unit of s. According to Figure $4, \varphi_{i, i+1}=t_{i, i+1}+t_{w^{\prime}}-G_{i+1}$ and $\left(R_{i+1}+t_{c}\right) q_{i, i+1}=t_{c} M_{i+1}$ can be obtained. Consequently, the queue dissipation time $t_{c}$ can be calculated with Equation (19).

$$
t_{c}=\frac{R_{i+1} q_{i, i+1}}{M_{i+1}-q_{i, i+1}}
$$

Similarly, the shaded area in Figure 4 shows the eastbound delay between intersections $P_{i}$ and $P_{i+1}$, denoted as $d_{i, i+1}^{2}$ in the unit of $\mathrm{s}$, and it can be calculated with Equation (20).

$$
d_{i, i+1}^{2}=\frac{1}{2} R_{i+1} q_{i, i+1}\left(R_{i+1}+t_{c}\right)
$$

Substitute Equation (19) into Equation (20) and simplify. Thus, Equation (21) is derived.

$$
d_{i, i+1}^{2}=\frac{R_{i+1}^{2} M_{i+1} q_{i, i+1}}{2\left(M_{i+1}-q_{i, i+1}\right)}
$$

Additionally, suppose $h_{i, i+1}^{2}$ is the eastbound vehicle stops at the intersection $P_{i+1}$ in the unit of veh. $h_{i, i+1}^{2}$ can be calculated with Equation (22).

$$
h_{i, i+1}^{2}=q_{i, i+1}\left(R_{i+1}+t_{c}\right)=\frac{R_{i+1} M_{i+1} q_{i, i+1}}{M_{i+1}-q_{i, i+1}}
$$

Based on the above two different situations of traffic flow for the platoon, delays of the eastbound platoon denoted as $D_{1}$ can be obtained, as shown in Equation (23).

$$
\begin{aligned}
D_{1} & =\sum_{i=1}^{n-1}\left[\alpha_{i} d_{i, i+1}^{1}+\left(1-\alpha_{i}\right) d_{i, i+1}^{2}\right] \\
& =\sum_{i=1}^{n-1}\left[\alpha_{i} \cdot \frac{\left(\varphi_{i, i+1}-t_{i, i+1}\right)^{2} M_{i+1} q_{i, i+1}}{2\left(M_{i+1}-q_{i, i+1}\right)}+\left(1-\alpha_{i}\right) \cdot \frac{R_{i+1}{ }^{2} M_{i+1} q_{i, i+1}}{2\left(M_{i+1}-q_{i, i+1}\right)}\right] \\
& =\sum_{i=1}^{n-1}\left\{\alpha_{i} \cdot \frac{\left[\varphi_{i, i+1}-\frac{L_{i, i+1}}{v_{i, i+1}}(\bmod T)\right]^{2} M_{i+1} q_{i, i+1}}{2\left(M_{i+1}-q_{i, i+1}\right)}+\left(1-\alpha_{i}\right) \cdot \frac{R_{i+1}{ }^{2} M_{i+1} q_{i, i+1}}{2\left(M_{i+1}-q_{i, i+1}\right)}\right\}
\end{aligned}
$$

where, $\alpha_{i}=\left\{\begin{array}{ll}1 & \text { the front part of platoon is blocked } \\ 0 & \text { the central or tail part of platoon is blocked }\end{array}\right.$ and $n$ is the total number of intersections.

Delays of the westbound platoon, denoted as $D_{2}$, can be obtained by a similar method. According to the principle of arterial coordinated control, the sum of the relative offsets equals the cycle length for opposite directions between adjacent intersections on arterial roads, that is, $\varphi_{i+1, i}=T-\varphi_{i, i+1}$. Substitute the above expression into Equation (23), and delays of the westbound platoon are derived, as shown in Equation (24).

$$
\begin{aligned}
D_{2} & =\sum_{i=1}^{n-1}\left[\beta_{i} d_{i+1, i}^{1}+\left(1-\beta_{i}\right) d_{i+1, i}^{2}\right] \\
& =\sum_{i=1}^{n-1}\left\{\beta_{i} \cdot \frac{\left[T-\varphi_{i, i+1}-\frac{L_{i+1, i}}{v_{i+1, i}}(\bmod T)\right]^{2} M_{i} q_{i+1, i}}{2\left(M_{i}-q_{i+1, i}\right)}+\left(1-\beta_{i}\right) \cdot \frac{R_{i}{ }^{2} M_{i} q_{i+1, i}}{2\left(M_{i}-q_{i+1, i}\right)}\right\}
\end{aligned}
$$

where, $\beta_{i}= \begin{cases}1 & \text { the front part of platoon is blocked } \\ 0 & \text { the central or tail part of platoon is blocked }\end{cases}$

In summary, the primary objective can be derived, as shown in Equation (25). 


$$
\begin{aligned}
& \min D: D=D_{1}+D_{2} \\
& \text { s.t. }\left\{\begin{array}{l}
0 \leq \varphi_{i, i+1} \leq T \\
0 \leq\left[\frac{L_{i, i+1}}{v_{i, i+1}}\right](\bmod T) \leq T
\end{array}\right.
\end{aligned}
$$

\subsubsection{Secondary Objectives}

Situations of traffic flow for the platoon on arterial roads were also divided into two categories for secondary objective modeling. The emission estimation model in the eastbound direction was established first.

1. The front part of platoon is blocked.

All platoon operating modes between the adjacent intersections are considered. Considering the time consumption $t_{w}$ and the eastbound vehicle stops $h_{i, i+1}^{1}$, the emissions from the eastbound platoon between adjacent intersections on the arterial roads can be derived from Equation (13), as shown in Equation (26).

$$
e_{i, i+1}^{1}=a e_{1}+b e_{2}+c e_{3}+d e_{3}
$$

where $e_{i, i+1}^{1}$ is the emissions from eastbound platoon between adjacent intersections on arterial roads when the front part of platoon is blocked, in the unit of $\mathrm{g}$.

2. The central or tail part of platoon is blocked.

All platoon operating modes between the adjacent intersections are also considered. However, the time consumption and the eastbound vehicle stops have been changed. Considering $t_{w}^{\prime}$ and $h_{i, i+1}^{2}$ for this situation, the emissions are calculated with Equation (27).

$$
e_{i, i+1}^{2}=a e^{\prime}{ }_{1}+b e^{\prime}{ }_{2}+c e^{\prime}{ }_{3}+d e^{\prime}{ }_{4}
$$

where $e_{i, i+1}^{2}$ is the emissions from the eastbound platoon between adjacent intersections on arterial roads when the central or tail part of platoon is blocked, in the unit of $\mathrm{g}$.

Suppose that $e_{i+1, i}^{1}$ and $e_{i+1, i}^{2}$ are the emissions from westbound platoon between adjacent intersections on arterial roads under two different situations of traffic flow, respectively. $e_{i+1, i}^{1}$ and $e_{i+1, i}^{2}$ can be derived by substituting $\varphi_{i+1, i}=T-\varphi_{i, i+1}$ into Equations (26) and (27). Consequently, the secondary objective can be obtained, as shown in Equation (28).

$$
\begin{aligned}
& \min E: E=\sum_{i=1}^{n-1} \alpha_{i} e_{i, i+1}^{1}+\left(1-\alpha_{i}\right) e_{i, i+1}^{2}+\sum_{i=1}^{n-1} \beta_{i} e_{i+1, i}^{1}+\left(1-\beta_{i}\right) e_{i+1, i}^{2} \\
& \text { s.t. }\left\{\begin{array}{l}
0 \leq \varphi_{i, i+1} \leq T \\
0 \leq\left[\frac{L_{i, i+1}}{v_{i, i+1}}\right](\bmod T) \leq T
\end{array}\right.
\end{aligned}
$$

where $n$ is the total number of intersections, and $\alpha_{i}, \beta_{i} \in(1,0)$.

\subsection{Solution Method}

The model developed in this paper is a multi-objective mixed integer programming model. Methods of multi-objective optimization usually include the weighting method, efficacy coefficient method, and hierarchical method. The weighting method may fail in generating the Pareto optimal set of a multi-criterion problem in non-convex cases [32]. The efficiency coefficient method is also called the efficiency function method. In this method, the parameters are transformed into measurable scores by the efficiency function. The merits and demerits are judged by the scores. The hierarchical method usually has some advantages when the target priority of the multi-objective optimization is certain. The hierarchical method is to obtain the optimal solution of each objective according to 
the preset priority of each objective. In the solving process, the optimal solution of the objective with lower priority is searched in the solution set of the objective with higher priority. However, the demerit of hierarchical method is that the solution will be interrupted when one of the objective functions has only one unique solution. In this paper, a modified hierarchical method has been employed to solve the offset optimization model. The model is decomposed into two single-objective optimization models, first based on the objective priority, and the optimal solution is then obtained combining the branch and bound approach.

Consequently, the solution process is divided into two steps. The first step is to find the minimum delay of the offset optimization model, considering delays of the platoon. In the second step, the optimal offsets between the arterial intersections are obtained under the constraint of the minimum delay calculated in the first step, which is the optimal value of the bi-objective optimization model developed in this paper. The minimum emission is also obtained in the second step.

- $\quad$ Step 1. Delay optimization

As shown in Equation (29), suppose that $D_{1}^{*}$ and $\varphi_{1}^{*}$ are the minimum delay and optimal offset produced by this step. $D_{1}^{*}$ and $\varphi_{1}^{*}$ can be obtained using the branch and bound approach by LINGO (Linear Interactive and General Optimizer).

$$
\left\{\begin{array}{l}
\min D(\varphi) \\
\text { S.t. } 0 \leq \varphi_{i, i+1} \leq T \\
0 \leq\left[\frac{L_{i, i+1}}{v_{i, i+1}}\right](\bmod T) \leq T
\end{array}\right.
$$

- $\quad$ Step 2. Offset optimization

In this step, the relaxation coefficient $\lambda$ is used to relax $D_{1}^{*}$, and the paper regards $D(\varphi) \leq D_{1}^{*}\left(\varphi_{1}^{*}\right) \cdot(1+\lambda)$ as a new constraint, as shown in Equation (30). Suppose that $E^{*}$ and $\varphi^{*}$ are the minimum emission and optimal offset produced by this step. $E^{*}$ and $\varphi^{*}$ can be obtained using the branch and bound approach by LINGO.

$$
\left\{\begin{array}{l}
\min E(\varphi) \\
\text { S.t. } 0 \leq \varphi_{i, i+1} \leq T \\
0 \leq\left[\frac{L_{i, i+1}}{v_{i, i+1}}\right](\bmod T) \leq T \\
D(\varphi) \leq D_{1}^{*}\left(\varphi_{1}^{*}\right) \cdot(1+\lambda)
\end{array}\right.
$$

where $\varphi^{*}$ is the optimal offset of the bi-objective optimization model developed in this paper.

\section{Case Study}

\subsection{Data Collection}

Xi Dajie Road in Beijing was taken as an example to prove the applicability of the bi-objective offset optimization model and the solution method in this paper. $X_{i}$ Dajie Road is one of the urban arterial roads in Beijing. The road is located in the north-central Xi Cheng District, from Di'an Men in the east to Guan'yuan Qiao in the west. The total length of Xi Dajie Road is approximately $1.5 \mathrm{~km}$. Based on the field survey, four intersections along Xi Dajie Road were chosen for analysis, as shown in Figure 5. The circles mark the intersection positions. 


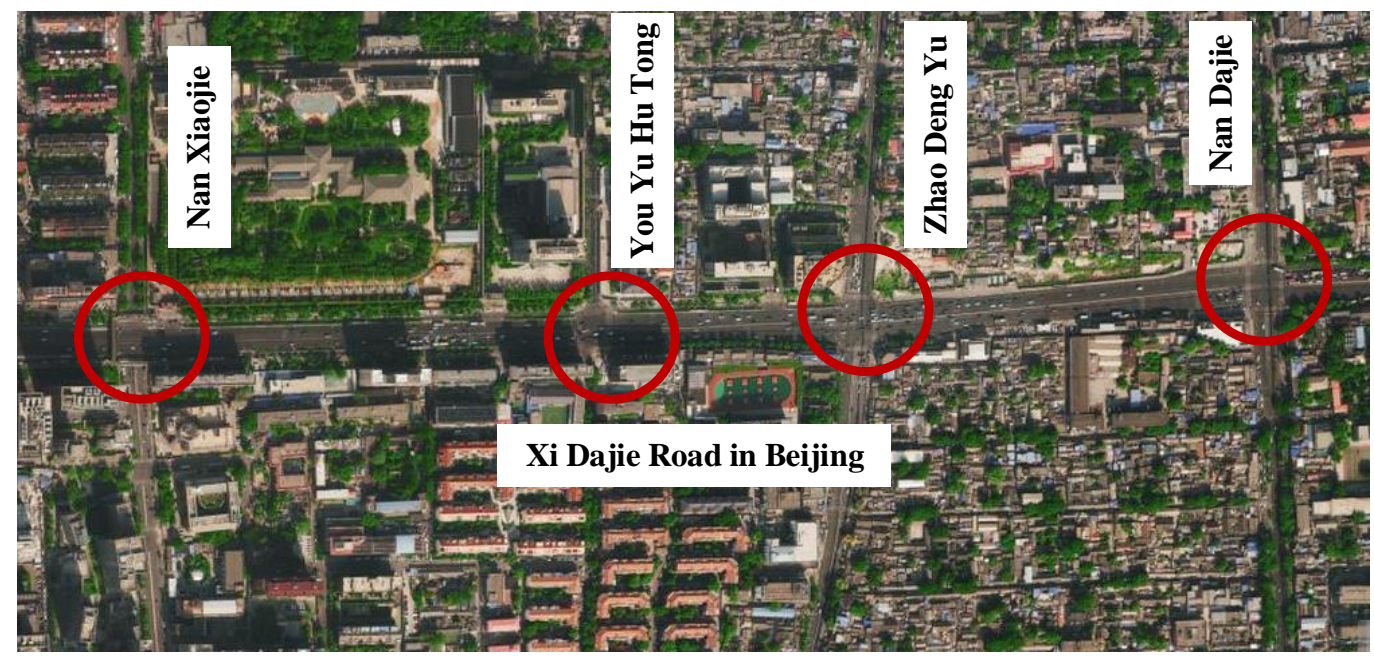

Figure 5. Top-down view of Xi Dajie Road in Beijing.

In order to calculate the delay and emissions of the platoon on Xi Dajie Road, it was necessary to investigate the traffic volumes between intersections. A total of ten hours were investigated at intervals of one hour. The model parameters can be summarized as shown in Tables 4 and 5 through the field survey results and literature review [33]. As for the relaxation coefficient, the value in this paper was 0.05 . The application and comparison of different relaxation coefficient values will be considered in the future.

Table 4. The arrival rate $q$ of Xi Dajie Road.

\begin{tabular}{|c|c|c|c|c|c|c|c|c|c|c|c|c|}
\hline \multirow{2}{*}{ Hours } & \multicolumn{2}{|c|}{$q_{1,2}($ veh $/ \mathrm{h})$} & \multicolumn{2}{|c|}{$q_{2,3}(\mathrm{veh} / \mathrm{h})$} & \multicolumn{2}{|c|}{$q_{3,4}(\mathrm{veh} / \mathrm{h})$} & \multicolumn{2}{|c|}{$q_{2,1}(\mathrm{veh} / \mathrm{h})$} & \multicolumn{2}{|c|}{$q_{3,2}($ veh/h) } & \multicolumn{2}{|c|}{$q_{4,3}(\mathrm{veh} / \mathrm{h})$} \\
\hline & Car & Bus & Car & Bus & Car & Bus & Car & Bus & Car & Bus & Car & Bus \\
\hline 1 & 1797 & 36 & 1899 & 35 & 1770 & 31 & 1818 & 38 & 1821 & 35 & 1785 & 36 \\
\hline 2 & 1868 & 40 & 1917 & 39 & 1815 & 38 & 1802 & 39 & 1799 & 42 & 1816 & 43 \\
\hline 3 & 1813 & 34 & 1870 & 33 & 1856 & 33 & 1859 & 36 & 1862 & 33 & 1767 & 31 \\
\hline 4 & 1752 & 44 & 1859 & 42 & 1852 & 43 & 1738 & 41 & 1737 & 42 & 1845 & 41 \\
\hline 5 & 1828 & 37 & 1831 & 36 & 1752 & 36 & 1872 & 38 & 1875 & 35 & 1800 & 37 \\
\hline 6 & 1901 & 41 & 1851 & 40 & 1813 & 39 & 1869 & 37 & 1868 & 38 & 1870 & 46 \\
\hline 7 & 1717 & 29 & 1929 & 26 & 1779 & 28 & 1774 & 28 & 1772 & 30 & 1833 & 31 \\
\hline 8 & 1830 & 30 & 1883 & 30 & 1702 & 34 & 1765 & 34 & 1767 & 32 & 1886 & 35 \\
\hline 9 & 1727 & 28 & 1851 & 32 & 1828 & 33 & 1670 & 29 & 1666 & 33 & 1807 & 31 \\
\hline 10 & 1784 & 45 & 1820 & 38 & 1849 & 43 & 1865 & 40 & 1868 & 37 & 1797 & 38 \\
\hline
\end{tabular}

Table 5. Summary of model parameters.

\begin{tabular}{ccc}
\hline Types & Parameters & Values \\
\hline & $L_{1,2}$ & 470 \\
Intersection Distance $(\mathrm{m})$ & $L_{2,3}$ & 280 \\
& $L_{3,4}$ & 420 \\
Signal Timing (s) & $T$ & 105 \\
Capacity (pcu/h) & $G_{1}, G_{2}, G_{3}, G_{4}$ & $49,50,50,47$ \\
Average Speed of the Platoons (m/s) & $M_{1}, M_{2}, M_{3}, M_{4}$ & $2100,2143,2143,2014$ \\
& $v_{1,2}, v_{2,3}, v_{3,4}$ & $8.5,7.5,8.5$ \\
Weight Coefficient of the Emissions & $\gamma_{1}$ for $\mathrm{NOx}$ & 0.4 \\
& $\gamma_{2}$ for $\mathrm{HC}$ & 0.2 \\
& $\gamma_{3}$ for CO & 0.4 \\
\hline
\end{tabular}




\subsection{Results}

Optimal offsets were obtained for the offset optimization, considering both delays and emissions of the platoon using the modified hierarchical method. Delays and emissions of the platoon under the optimal offsets were also obtained. In order to prove the applicability of the model established in this paper, the proposed offset optimization model was compared with the existing timing plan and the offset optimization considering delays only. Furthermore, the paper defines the existing timing plan, the offset optimization considering delays only, and the offset optimization considering both delays and emissions of the platoon as Scenario 1, Scenario 2, and Scenario 3, respectively. The results of the comparison are shown in Tables 6 and 7 and Figure 6.

Table 6. Optimal offsets of three scenarios.

\begin{tabular}{cccccccccc}
\hline \multirow{2}{*}{ Hours } & \multicolumn{3}{c}{ Scenario 1 Existing } & \multicolumn{3}{c}{$\begin{array}{c}\text { Scenario 2 Considering } \\
\text { Delays }\end{array}$} & \multicolumn{3}{c}{$\begin{array}{c}\text { Scenario 3 Considering } \\
\text { Delays and Emissions }\end{array}$} \\
\cline { 2 - 9 } & $\varphi_{1,2}(\mathbf{s})$ & $\varphi_{2,3}(\mathbf{s})$ & $\varphi_{3,4}(\mathbf{s})$ & $\boldsymbol{\varphi}_{1,2}(\mathbf{s})$ & $\boldsymbol{\varphi}_{2,3}(\mathbf{s})$ & $\boldsymbol{\varphi}_{3,4}(\mathbf{s})$ & $\boldsymbol{\varphi}_{1,2}(\mathbf{s})$ & $\boldsymbol{\varphi}_{2,3}(\mathbf{s})$ & $\boldsymbol{\varphi}_{3,4}(\mathbf{s})$ \\
\hline 1 & 60 & 36 & 54 & 51.7 & 51.3 & 52.8 & 49.6 & 52.1 & 55.4 \\
2 & 60 & 36 & 54 & 53.1 & 47.1 & 52.9 & 54.1 & 49.6 & 55.6 \\
3 & 60 & 36 & 54 & 51.2 & 52.0 & 53.2 & 49.7 & 52.2 & 56.6 \\
4 & 60 & 36 & 54 & 52.4 & 49.4 & 53.1 & 52.1 & 50.5 & 56.0 \\
5 & 60 & 36 & 54 & 51.1 & 50.4 & 52.7 & 48.1 & 51.6 & 54.3 \\
6 & 60 & 36 & 54 & 52.6 & 50.9 & 52.7 & 52.6 & 52.7 & 55.9 \\
7 & 60 & 36 & 54 & 51.4 & 45.9 & 52.7 & 49.5 & 49.0 & 53.9 \\
8 & 60 & 36 & 54 & 53.0 & 50.7 & 52.3 & 54.2 & 52.1 & 48.7 \\
9 & 60 & 36 & 54 & 52.9 & 51.5 & 53.0 & 53.4 & 52.0 & 56.4 \\
10 & 60 & 36 & 54 & 50.7 & 55.3 & 53.2 & 48.8 & 54.5 & 56.2 \\
\hline
\end{tabular}

Table 7. Arterial delays and emissions of three scenarios.

\begin{tabular}{ccccccc}
\hline Hours & \multicolumn{2}{c}{ Scenario 1 Existing } & \multicolumn{2}{c}{$\begin{array}{c}\text { Scenario 2 Considering } \\
\text { Delays }\end{array}$} & \multicolumn{2}{c}{$\begin{array}{c}\text { Scenario 3 Considering } \\
\text { Delays and Emissions }\end{array}$} \\
\hline & Delays (s) & $\begin{array}{c}\text { Emissions } \\
\mathbf{( g )}\end{array}$ & Delays (s) & $\begin{array}{c}\text { Emissions } \\
\text { (g) }\end{array}$ & Delays (s) & $\begin{array}{c}\text { Emissions } \\
\text { (g) }\end{array}$ \\
\hline 1 & 2570.1 & 6253.7 & 1626.7 & 6167.3 & 1662.5 & 5812.6 \\
2 & 1712.8 & 6431.2 & 1411.4 & 6348.2 & 1473.1 & 5990.0 \\
3 & 2410.5 & 6270.8 & 1513.8 & 6164.2 & 1577.9 & 5810.9 \\
4 & 1724.9 & 6385.7 & 1228.2 & 6316.8 & 1283.8 & 5964.1 \\
5 & 1677.6 & 6311.5 & 1237.1 & 6192.7 & 1287.0 & 5838.8 \\
6 & 1983.5 & 6538.7 & 1440.3 & 6424.9 & 1501.7 & 6061.7 \\
7 & 1434.4 & 5973.0 & 1194.4 & 5900.3 & 1246.7 & 5552.5 \\
8 & 2147.8 & 6154.5 & 1423.5 & 6078.9 & 1481.0 & 5725.6 \\
9 & 2062.8 & 5984.6 & 1263.0 & 5931.2 & 1318.6 & 5585.2 \\
10 & 2967.8 & 6466.8 & 1500.1 & 6358.7 & 1563.3 & 5999.3 \\
\hline
\end{tabular}




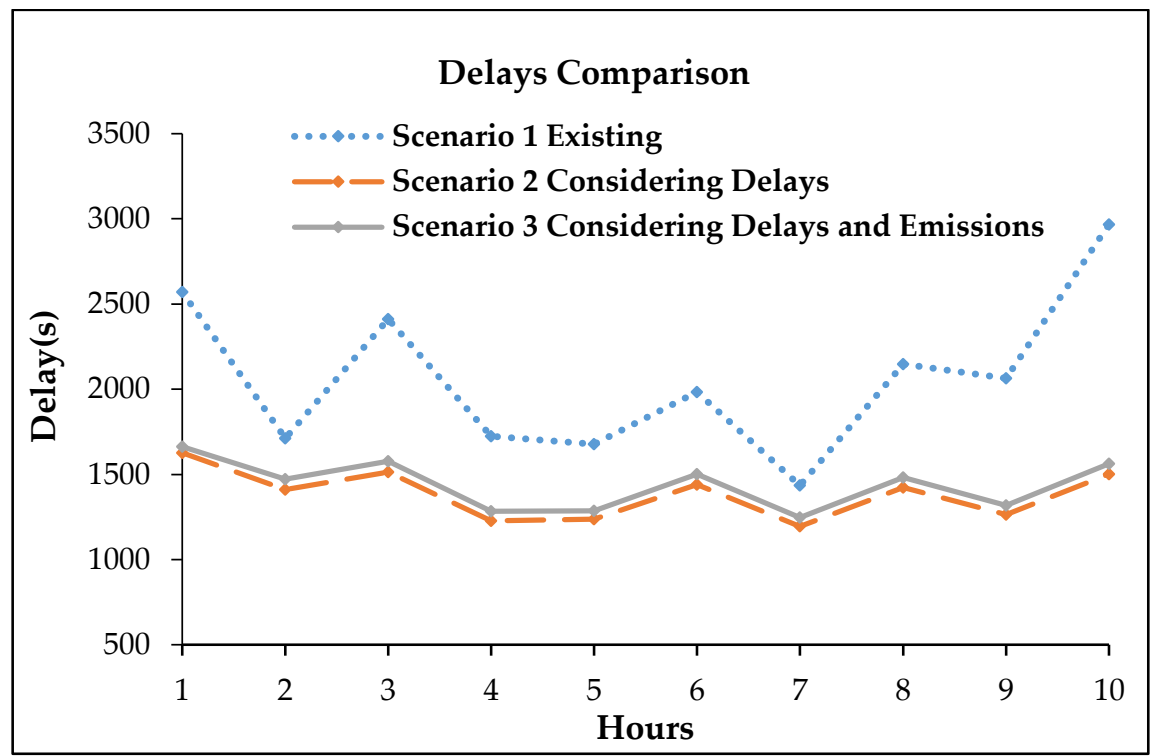

(a) Delays comparison

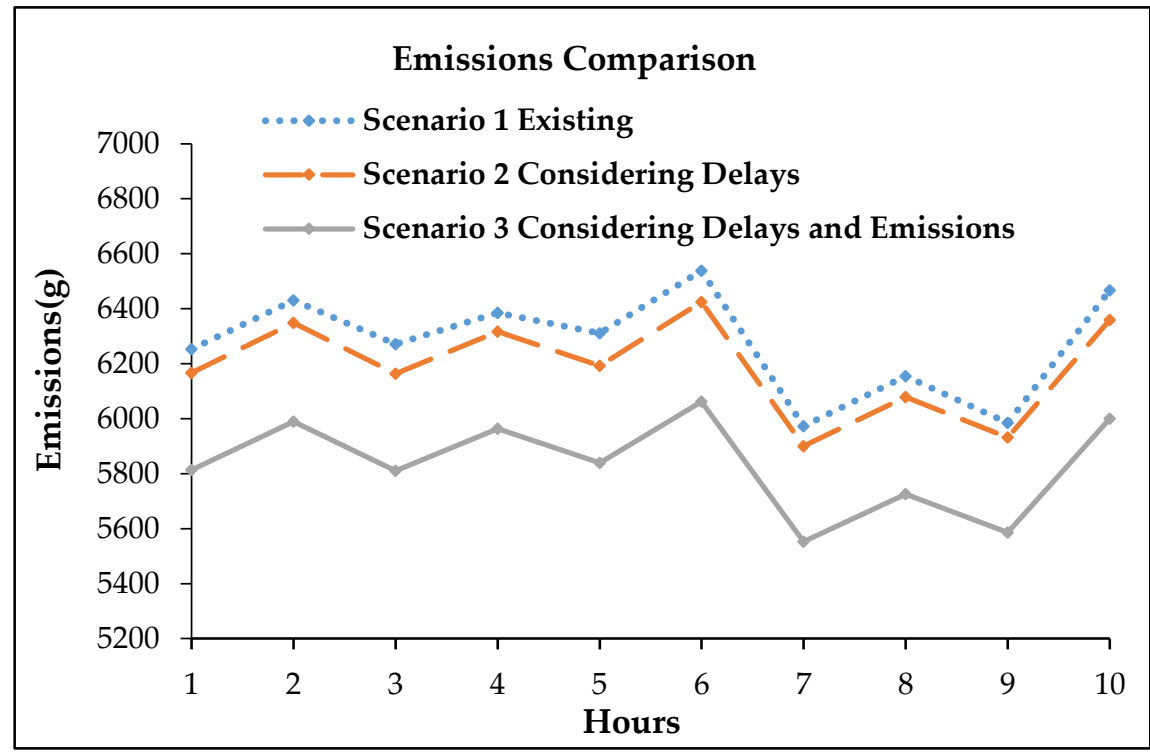

(b) Emissions comparison

Figure 6. Comparison of delays and emissions of three scenarios.

\subsection{Discussions}

For delays comparison, as shown in Figure 6a, the delays of Scenario 2 and Scenario 3 were reduced compared with Scenario 1. The delays of Scenario 3 were increased compared with Scenario 2, and the average growth rate did not exceed 3\%. For emissions comparison, as shown in Figure 6b, the emissions of Scenario 1, Scenario 2, and Scenario 3 were reduced gradually. The emissions of Scenario 2 were slightly lower compared with Scenario 1, with the average reduction rate less than $3 \%$. However, the emissions of Scenario 3 were significantly lower than that of Scenario 2, with a minimum reduction rate of $6.6 \%$ and a maximum reduction rate of $7.5 \%$. This indicates that offset optimization considering both delays and emissions of the platoon can effectively reduce emissions of the platoon on arterial roads while reducing delays. In order to reduce the severe air pollution in China, considering emissions of the platoon in arterial offset optimization should be pursued. Scenario 
3 reduced not only delays, but also reduced emissions of the platoon on arterial roads significantly. We conclude that Scenario 3 is the best solution.

Furthermore, only passenger cars and buses were considered in the optimization model, and the effects of trucks and pedestrians on the artery are not included. Therefore, there are still some limitations for the model in this paper that need to be improved in the future. For example, the applicability of the model may be poor for the arterial offset optimization with more trucks and pedestrians.

\section{Conclusions and Recommendations}

This paper developed a bi-objective offset optimization model, in which minimizing delays and emissions of the platoon on arterial roads were the primary and secondary objectives, respectively. The modified hierarchical method combining the branch and bound approach with introduction of a relaxation coefficient can effectively overcome the shortcomings of the traditional hierarchical method. Our case study used Xi Dajie Road in Beijing as an example to verify the advantages of the model, and the main conclusions are as follows:

1. For delays, the bi-objective offset optimization model reduced delays by up to $20 \%$ compared with the existing timing plan, and increased delays by no more than $3 \%$ compared with the optimal model considering delays only.

2. For emissions, the bi-objective offset optimization model reduced $7 \%$ of emissions compared with the existing timing plan, and reduced $6 \%$ of emissions compared with the optimization model considering delays only, which demonstrates that the bi-objective offset optimization model established in this paper is better than the other two scenarios in reducing emissions of the platoon.

It is recommended that emissions of the platoon be considered for offset optimization. In this paper, the optimal offsets of arterial roads were obtained considering delays and emissions of the platoon. More factors are recommended to be considered for further studies, such as the satisfaction degree of drivers and fuel consumption. In the future, different methods of multi-objective optimization will be employed to solve the model and compare the performance with the proposed modified hierarchical method in this paper.

Author Contributions: S.D. and X.W. participated in the acquisition and processing of data; S.D., X.C., X.W. and L.Y. developed the proposed model in this paper; S.D., X.C., and L.Y. performed all analyses; S.D., X.C. prepared the draft manuscript; All authors reviewed the results and approved the final version of the manuscript.

Funding: This research was funded by the National Natural Science Foundation of China (NSFC) under grant number 71871013.

Conflicts of Interest: The authors declare no conflict of interest.

\section{References}

1. Federal Highway Administration. Traffic Control Systems Handbook; Federal Highway Administration: Washington, DC, USA, 2005.

2. Guo, Y.H.; Wang, Z.F.; Kang, H. Impact of Automobile Vehicles Exhaust Emissions on Metropolitan Air Quality: Analysis Study on the Air Pollution Change before and after the Spring Festival in Urumqi City, China. Acta Sci. Circumstantiae 2014, 34, 1109-1117.

3. Jimenez-Palacios, J.L. Understanding and Quantifying Motor Vehicle Emissions with Vehicle Specific Power and TILDAS Remote Sensing. Ph.D. Thesis, Massachusetts Institute of Technology, Cambridge, MA, USA, 1998.

4. Hao, Y.Z.; Yu, L.; Song, G.H.; Wang, H.T. A study on Driving and Emission Features of Diesel Buses in Beijing Based on VSP Parameter. Automot. Eng. 2010, 32, 103-109.

5. Zhai, Z.Q.; Song, G.H.; Lu, H.Y. Validation of Temporal and Spatial Consistency of Facility- and Speed-specific VSP Distribution for Emission Estimation: A Case Study in Beijing. J. Air Waste Manag. Assoc. 2017, 67, 949-957. [CrossRef] [PubMed] 
6. Zang, L.L.; Jia, L.; Meng, X.X. An Optimization Control Algorithm of Traffic Signals for Urban Arterials. In Proceedings of the 2009 IITA International Conference on Control, Automation and Systems Engineering, Zhangiiajie, China, 11-12 July 2009.

7. Hu, H.; Liu, H.X. Arterial Offset Optimization Using Archived High-resolution Traffic Signal Data. Transp. Res. Part C Emerg. Technol. 2013, 37, 131-144. [CrossRef]

8. Christofa, E.; Ampountolas, K.; Skabardonis, A. Arterial Traffic Signal Optimization: A Person-based Approach. Transp. Res. Part C Emerg. Technol. 2016, 66, 27-47. [CrossRef]

9. Chen, X.; Zhang, C. Graphic Method of Bidirectional Green Wave Control Based on Centerline Intersection of Green Wave Band. J. Liaoning Univ. Technol. 2017, 37, 137-140.

10. Little, J. The Synchronization of Traffic Signals by Mixed-integer Linear Programming. Oper. Res. 1966, 14, 568-594. [CrossRef]

11. Wu, X.Y.; Tian, Z.; Hu, P.F.; Yuan, Z.Z. Bandwidth Optimization of Coordinated Arterials Based on Group Partition Method. Procedia-Soc. Behav. Sci. 2012, 43, 232-244. [CrossRef]

12. Guo, L.; Yang, R.; Zhang, M. Arterial Traffic Two-direction Green Wave Coordination Control Based on MATLAB Graphical Method. In Proceedings of the 2nd International Conference on Information Science and Control Engineering, Shanghai, China, 24-26 April 2015.

13. Gomes, G. Bandwidth Maximization Using Vehicle Arrival Functions. IEEE Trans. Intell. Transp. Syst. 2015, 16, 1977-1988. [CrossRef]

14. Zhang, L.; Song, Z.; Tang, X.; Wang, D. Signal Coordination Models for Long Arterials and Grid Networks. Transp. Res. Part C Emerg. Technol. 2016, 71, 215-230. [CrossRef]

15. Shirvani, M.J.; Maleki, H.R. Enhanced Variable Bandwidth Progression Optimization Model in Arterial Traffic Signal Control. IET Intell. Transp. Syst. 2016, 10, 396-405. [CrossRef]

16. Giovanni, D.N.; Gabriel, G.; Horowitz, R.; Moulin, P. Speed Advisory and Signal Offsets Control for Arterial Bandwidth Maximization and Energy Consumption Reduction. IEEE Trans. Control Syst. Technol. 2017, 25, $1-13$.

17. Lu, K.; Huang, J.; Xu, J. An New Offset Model for Arterial Road Coordinate Control and Its Optimization Method. China J. Highw. Transp. 2008, 21, 15-20.

18. Li, X.H.; Tan, G.Z.; Chen, C. Urban Arterial Road Green-wave Control Based on Genetic Algorithm. In Proceedings of the 7th World Congress on Intelligent Control and Automation, Chongqing, China, 25-27 June 2008.

19. He, Q.; Head, K.L.; Ding, J. Multi-modal Traffic Signal Control with Priority, Signal Actuation and Coordination. Transp. Res. Part C 2014, 46, 65-82. [CrossRef]

20. Song, X.M.; Tao, P.F.; Chen, L.G.; Wang, D.H. Offset Optimization Based on Queue Length Constraint for Saturated Arterial Intersections. Discret. Dyn. Nat. Soc. 2012, 2012, 1-13. [CrossRef]

21. Li, X.; Li, G.; Pang, S.S.; Yang, X.G.; Tian, J.L. Signal Timing of Intersections Using Integrated Optimization of Traffic Quality, Emissions and Fuel Consumption: A Note. Transp. Res. Part D 2004, 9, 401-407. [CrossRef]

22. Liao, T.; Machemehl, R. Optimal Traffic Signal Strategy for Fuel Consumption and Emissions Control at Signalized Intersections. In Proceedings of the 24th European Transport Forum, Brunel University, London, England, 2-6 September 1996.

23. Park, B.; Yun, I.Y.; Ahn, K. Stochastic Optimization of Sustainable Traffic Signal Control. Int. J. Sustain. Transp. 2009, 3, 263-284. [CrossRef]

24. Stevanovic, A.; Stevanovic, J.; Zhang, K.; Batterman, S. Optimizing Traffic Control to Reduce Fuel Consumption and Vehicular Emissions: Integrated Approach with VISSIM, CMEM, and VISGAOST. J. Transp. Res. Board 2009, 2128, 105-113. [CrossRef]

25. Ma, D.P.; Nakamura, H. Cycle Length Optimization at Isolated Signalized Intersections from the Viewpoint of Emission. In Traffic and Transportation Studies 2010; American Society of Civil Engineers (ASCE): Reston, VA, USA; pp. 275-284.

26. Madireddy, M.; Coensel, B.D.; Can, A.; Degraeuwe, B.; Beusen, B.; Vlieger, I.D.; Botteldooren, D. Assessment of the Impact of Speed Limit Reduction and Traffic Signal Coordination on Vehicle Emissions Using an Integrated Approach. Transp. Res. Part D 2011, 16, 504-508. [CrossRef]

27. Day, C.M.; Brennan, T.M., Jr.; Hainen, A.M.; Remias, S.M.; Premachandra, H. Reliability, Flexibility, and Environmental Impact of Alternative Objective Functions for Arterial Offset Optimization. J. Transp. Res. Board 2011, 16, 8-22. [CrossRef] 
28. Zhang, L.H.; Yin, Y.; Chen, S. Robust Signal Timing Optimization with Environmental Concerns. Transp. Res. Part C Emerg. Technol. 2013, 29, 55-71. [CrossRef]

29. Chen, X.M.; Yu, L.; Song, G.H.; Xian, C.Y. Comparative Study of Emissions from Bus Rapid Transit and Conventional Bus System: A Case Study of Beijing. J. Transp. Res. Board 2012, 2277, 11-20. [CrossRef]

30. Song, G.H.; Yu, L.; Xu, L. Comparative Analysis of Car-following Models for Emissions Estimation. J. Transp. Res. Board 2013, 2341, 12-22. [CrossRef]

31. Wang, Y.H.; Chen, X.M.; Liu, Q.; Li, M. Emission Analysis for a Transit Corridor under Different Improvement Strategies. J. Transp. Res. Board 2016, 2570, 69-76. [CrossRef]

32. Koski, J. Defectiveness of weighting method in multicriterion optimization of structures. Commun. Appl. Numer. Methods 1985, 1, 333-337. [CrossRef]

33. Xie, L.Z. Transit Signal Priority Control Strategy and Microscopic Simulation Research Considering Vehicle Exhaust Emission Factor. Master Thesis, Beijing Jiaotong University, Beijing, China, 2015.

(C) 2019 by the authors. Licensee MDPI, Basel, Switzerland. This article is an open access article distributed under the terms and conditions of the Creative Commons Attribution (CC BY) license (http://creativecommons.org/licenses/by/4.0/). 